\title{
LA LIBERTAD
}

\section{EN EL MUNDO ANTIGUO}

\section{Dr. Francisco Vindas Ch.}

Tácito concluye su obra GERMANIA, hablando a sus lectores sobre los FENNOS: esta población vive en condiciones de miseria indescriptible, sin conocimiento alguno de la civilización. No tienen armas ni caballos; se alimentan de hierbas, se visten con pieles, la desnuda tierra tienen por lecho y su morada la encuentran debajo de las plantas. Y sin embargo prefieren esta clase de vida. Ellos, seguros en las relaciones de los hombres y de los dioses, han logrado una cosa muy difícil: no tienen ni siquiera necesidad de rezar.

De esta manera los Fennos son libres:diciendo no a todo el progreso del género humano, refutando usar las facultades que son propias de tode hombre .

Las palabras de Tácito, el gran historiador de Roma imperial, de la Roma que ha llevado a cabo el imperio universal: Securi adversus homines, securi adversos deos, rem difficilliman consecuti sunt, ut illis ne voto quidem opus esset ${ }^{1}$ ¿tienen acaso valor de cierto mensaje?

Los Fennos son los últimos seres humanos; más allá de ellos, según el decir de Tácito, están los Elusos y Osiones, que ciertamente tienen bocas y rostros humanos, pero cuerpos y miembros bestiales. Ya que de parte de los Fennos se hace oír una voz que condena las conquistas de la civilización y proclama la felicidad haciéndola consistir en la liberación de las necesidades, ¿deberá acaso la humanidad retroceder en el recorrido de la vía los siglos, para volver a encontrar la ansiada pureza de vida en la libertad de todo vínculo?

A la mente del historiador, que ha vivido per quindecim annos, grande mortalis aevi spatium ${ }^{2}$ en condición de esclavitud política y de construcción moral, el espléndido imperio que se extiende sobre

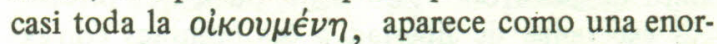
me prisión. El podỉa repetir las severas palabras amonestadoras referidas por lo menos medio siglo antes por el autor del Sublime:

" Nosotros hombres del mundo actual hemos crecido, como parece, en la escuela de una esclavitud legitima que con sus costumbres e instituciones nos ha estrujado en un haz por asi decirlo, desde el primer momento que comenzamos a tener uso de razón; y no hemos saboreado el agua de aquella fuente que es la más bella y fecunda de la elocuencia: la libertad, quiero decir, $\tau \dot{\eta} \nu$ $\dot{\epsilon} \lambda \epsilon v \theta \epsilon \rho i \alpha \nu$ $\lambda \epsilon ́ \gamma \omega$. Toda esclavitud, aun la más legitima, se podría definir jaula y prisión pública del alma ${ }^{3}$."

De esta prisión no se permite salir a fin de reconquistar la libertad si no es deseando un utópico retorno a la naturaleza.

Tácito no cree que la libertad pueda realmente instaurarse en Roma; esta desconfianza suya lo 
vuelve un tanto pesimista y lo induce a aconsejar obsequium et modestia hacia los tiranos, ya que él bien sabe que aún bajo príncipes malvados se puede ser gran hombre ${ }^{4}$; y lo induce también a juzgar con severidad excesiva aquellos espíritus nobles, que en un régimen de esclavitud, "por vana ostentación de libertad, despreciaron la vida y adquirieron gloria con muerte ambiciosa, sí, mas de ninguna utilidad para el estado"5. A Peto Trasea desaprueba que por no condividir la infamia en las adulaciones proferidas por el senado a favor del matricida Nerón, "salió del senado y esto fue para él causa de peligro en su seguridad personal sin que con esta actitud procurara a los otros un principio de libertad."6.

Pero la suerte quiso que los Anales de Tácito se interrumpieran precisamente con la narración del fin de Trasea, el cual, habiéndose abierto las venas y cayendo la sangre hasta el suelo, y llamando al cuestor que le había llevado la orden de morir, le dice: "Nosotros libamos en honor de Júpiter Libertador; tú, oh joven, mira ..."7

La civilización clásica cuando llegó al máximo punto de desarrollo, ¿no tiene, pues, que ofrecer más esperanza de libertad a los hombres con excepción de la alcanzada en la muerte?

Siendo vana la utopía de retornar a la naturaleza e inútiles los esfuerzos para conferir al Estado la antigua libertad, no quedaba más que morir tal como lo realizaron entre otros T. Labieno, Cremucio Cordo, Séneca, Trasea y tanto otros; o tal vez pasar de la juventud a la vejez y de ésta al umbral de la muerte en el silencio, per silentium ${ }^{8}$.

El último coloquio de Trasea, que escucha la orden de morir, se desenvuelve con Demetrio, maestro de la escuela cínica; y Séneca, el gran filósofo, después de haberse retirado sin más ilusiones del gobierno, exalta al mismo Demetrio como perfecto sabio.

\footnotetext{
"que la naturaleza concedió a nuestros tiempos para demostrar que ni él. puede ser corrompido por nosotros, ni nosotros podemos ser corrompidos por alguno". 9
}

Se trata de un mundo que no tiene ninguna esperanza de liberación: está llegando a su ocaso y éste es el aspecto dramático de su condición, y de esto tiene clara conciencia.

Pero no, aún existe una esperanza de liberación: ¿Por qué no instaurar el reino de los filósofos? En tiempos de la conjura de Pisón hubo quien pensó confiar el imperio a Séneca en virtud del esplendor de sus virtudes ${ }^{10}$; y Juvenal más tarde llega a exclamar:

"Si al pueblo se le concediese libertad de voto - libera suffragia- ¿quién seria tan descriteriado en dudar de anteponer Séneca a Nerón?" 11 .

También la Grecia del siglo IV. a C. en la época en la cual la libertad va lentamente pero inexo. rablemente disolviéndose, anhela la república de los filósofos como Platón primeramente llegó a manifestarlo ${ }^{12}$; o bien acoge con simpatía la propaganda cínica que tiende a conceder la liberación espiritual y por ende la libertad efectiva, a los individuos que viven en ciudades sometidas.

Mientras los habitantes de Corinto se aprestan a defenderse de Filipo, que se dirige contra laciudad, Diógenes, el Cínico, mata su tiempo haciendo rodar su barril para ser objeto de las befas de los corintios ${ }^{13}$.

He aquí come los Cínicos alcanzan la libertad.

"Libres del placer que es propio del escla. vo,

ellos aman a la inmortal reina de la liber. tad"14 $^{14}$

Así lo piensa Crates. Y Luciano:

"Piensa que experimentan más necesidades los niños que los adultos, más las mujeres que los varones, más los enfermos que los sanos; en general quien tiene menos experimenta más necesidades que el que tiene más. Por esto los dioses no tienen necesidad de nada: y quien está más cerca de los dioses tiene poquísimas necesida. des. $" 15$. 
Los Fennos, de quienes habla Tácito, están, por lo tanto, muy cerca de los dioses.

Pero esto significaría una condena sin apelación, de la sociedad, tanto de las leyes positivas como también de la familia; tanto del Estado como de la esclavitud: "El sabio se basta a sí mismo"16; " "El único verdadero estado lo constituye el mundo entero"17; Interrogado Diógenes de dónde era, CIUDADANO DEL MUNDO, respondió ${ }^{18}$.

No hay posibilidad de sustraerse a la férrea ley de la necesidad que consigo lleva corrupción y muerte, si no es con la liberación de las necesidades. Cuando el aristotélico Dicearco, escribe Bios $\mathrm{E} \lambda \lambda \dot{\alpha} \delta \delta_{0 \varsigma}$, historia de la civilización humana, concentra su interés sobre Grecia y ve un progresivo empobrecimiento del hombre en el pasaje desde la condición feliz de la mítica edad áurea a la infelicidad de los contemporáneos, que no obstante existen después de las conquistas de la civilización. El cielo aparece cerrado sobre los griegos del siglo de Platón y Aristóteles y sobre los Romanos del siglo de Séneca y de Tácito, el cual nos dice:

"Yo no sabría juzgar si los acontecimientos humanos se desarrollan de acuerdo con el destino y la necesidad inmutable o de acuerdo con lo imprevisto 19 ".

No hay más lugar para la libertad: o el destino (identificado con la inexorable necesidad) o la causalidad rigen la suerte humana. Tácito, historiador y artista a la vez, constituye un punto de referencia o acercamiento en la meditación del mundo antiguo en torno al problema de la libertad.

A quien vive en un estado regido por un tirano, Séneca le dirige insistentemente la exhortación de que busque su libertad en la muerte:

"Nosotros demostraremos que en toda esclavitud existe una senda expedita hacia la libertad. ¿Por qué gimes, tonto? ¿Por qué esperas que un enemigo te vengue con la ruina de tu pueblo o que un rey poderoso venga en tu auxilio desde lejos $A$ donde quiera que dirijas tu mirada, ahi está el fin de los males. ¿Ves aquel precipicio? Por ahi se desciende a la libertad.
¿Ves el mar, aquel rio, aquel pozo? Por esos lugares hay libertad: en el fondo. ¿Ves aquella planta, seca, pequeña, mortal? De ella depende tu libertad. ¿Ves tu garganta, tu cuello, tu corazón? Son vias de escape de la esclavitud. ¿Son salidas demasiado fatigosas éstas que te muestro $y$ que exigen mucho valor $y$ muchafuerza?

¿Deseas saber' cuál es el camino que conduce a la libertad? ¡Cualquier vena de tu cuerpo!" 20

Esta resuelta voluntad de sustraerse a la esclavitud no puede ser concebida sin convertirse en una oposición al Estado. Es algo negativo, pasivo, aunque nos parezca contradictorio y el propio Séneca nos advierte:

\begin{abstract}
"La libertad no consiste en no sufrir. Seria grave equivocación. Es auténtica libertad colocar el alma por encima de las ofensas y comportarse de tal manera que de si mismo solamente se tengan motivos. de gozo; $y$ apartarse de las cosas exteriores para no vivir una vida inquieta con el temor continuo de la risa y habladurías de todo el mundo." 1
\end{abstract}

La civilización clásica debe reconocer la propia incapacidad de satisfacer la necesidad de la libertad de los hombres; la sociedad organizada llega entonces a considerarse como un obstáculo de la libre expansión de la personalidad y del perfeccionamiento espiritual de los individuos; así la libertad viene a ser entendida como libertad del Estado. En Roma fueron los Sestos quienes de primeros en la edad de César y de Augusto, afirmaron con energía que el sabio tiene derecho de vivir libre, independiente del Estado. El sabio respeta el Estado, pero no participa de la vida política.

Esta forma de libertad podría mejor definirse como liberación, ésta aparece como cierta cosa inicial, como el primer paso dado sobre una senda cuya meta desconocemos. Sin embargo, bien lo sabía ya Cleante, maestro del Estoicismo, al cantar: 
"Guiame, oh Júpiter, y también tú, oh Destino, guiame hacia aquel punto que me habeis establecido; pronto seguiré; que si, para ser malvado, yo no lo deseara con todo debería seguiros" 22

Entonces, pues, para el hombre antiguo, ¿la libertad no es más que simple aceptación del destino? ¿Tan triste y desteñida es la suerte del hombre? ¿No le queda más al hombre, cual anillo de acero bien remachado en la cadena irrompible de la sucesión de causas y efectos, sino aceptar, plegarse de buen grado al destino?

Parece no existir otra coșa más. Y Séneca bien lo sabe, cuando a los ya citados versos de Cleante, añade:

\author{
"ducunt volentem fata, nolentem \\ trahunt",23
}

Pero, ¡carambas! , ¿es entonces la historia del mundo clásico una simple historia de una siempre más consciente negación de la libertad? Y en primer lugar, ¿el pensamiento clásico logró demostrar verdaderamente que el hombre es libre?

E1 hombre actúa en el tiempo; pero los antiguos llegaron a concebir los acontecimientos como desarrollados sobre un círculo. Dice al respecto Aristóteles:

"Si la sucesión de los acontecimientos es un círculo y ya que el círculo no tiene ni principio ni fin, no podemos nosotros, por una mayor cercinia al principio, ser anteriores a aquellos, es decir a quien ha existido primero que nosotros, y éstos, $i$ gualmente, no pueden ser anteriores a nosotros" 24

Cogido un punto sobre la circunferencia, no hay sentido en el hablar de anterioridad o posterioridad respecto a cualquier punto de la misma circunferencia. Esto está declarado explícitamente por Aristóteles mismo:

"En el movimiento rectilíneo se distin- guen el principio, fin y medio ..., pero en el circular no ... porque todo punto es igualmente principio, mitad y fin; asi que todo junto está siempre en el principio, en el medio $y$ en el fin $y$ no hay más." 25

De donde se sigue que la serie de los sucesos debe fatalmente repetirse: se podría, con un poco de audacia hasta decirse que el tiempo debe necesariamente retornar a los mismos acontecimientos. Escuchemos a Virgilio, en la Egloga Cuarta:

"Un nuevo Tifis entonces aparecerá y otra Argos, que lleve héroes esçogidos: de nuevo existirán aquellas guerras y de nuevo con dirección a Troya será enviado el gran Aquiles ${ }^{26}$."

El gran orden de las generaciones renace desde un principio", proclama el poeta mantovano: "magnus ab integro saeclorum nascitur ordo".

"ya también la Virgen regresa
y regresan los reinos saturnios" 7

Y en el poema Anquises muestra al hijo que desciende al Hades, "las almas, a quienes por destino les espera encarnarse otra vez", animae quibus altera fato/ corpora debentur ${ }^{28}$ desde Silvio, descendencia póstuma de Eneas, al joven Marcelo, nieto de Augusto.

Este es el destino del Ciclo de los acontecimientos humanos; la paligénesis que desde las doctrinas pitagóricas hasta las estoicas, domina las creencias de los antiguos. Y se admitía que ya Pitágoras así había enseñado:

"Según ciertos periodos lo que una vez sucede vuelve a presentarse; en realidad no hay nada nuevo."29 
"Sucederá de nuevo que Adán y Eva repitan lo que han hecho ya. . . También Judas traicionará dos veces al Señor y por segunda vez Pablo custodiará los vestidos de aquellos que apedreen a Esteban". 30

Así creían los antiguos. "Por esto los hombres mueren -observaba Alcmeón-porque no pueden soldar el principio con el fin."31 ; si pudieran verificar esto, tendríamos al círculo del tiempo, el cual es finito, pero que continúa siempre girando; es decir, los hombres se identificarían con el tiempo, lo cual Claudiano compara a la serpiente que se enrosca y se muerde la cola incesantemente ${ }^{32}$.

Concibiendo así el tiempo, el actuar de los hombres resulta predeterminado, ya que no puede sino simplemente repetir exactamente esto que ya verificó aquel "yo", que en mí mismo he renacido, en el "gran año" precedente a éste; y así se recorre hacia atrás y se avanza hacia adelante, de manera infinita, sin jamás encontrar un principio, un punto de partida. Yo, que en este momento existo, ya antes fui y lo que ahora realizo, ya antes lo hice; y no puede ser diverso de lo que soy y hacer otra cosa de aquella que hago. Así como en el perpetuo movimiento circular de todas las cosas, yo un día existiré de nuevo y no podré no ser de nuevo aquel que ahora soy y ya una vez fui y no realizar de nuevo esto que ahora hago y ya una vez realicé:

“idem semper erit, quoniam semper fuit $i$ dem" 33

Y Marco Aurelio así meditaba:

" ¿Cuántos Crisipos, cuántos Sócrates, cuántos Epitectos el tiempo ya se ha tragado! Debes también pensar que lo mismo sucede a todo otro hombre y a cualquier otra cosa ... Por esta razón es lo mismo investigar la vida humana por un espacio de cuarenta años, como por un espacio de diez mil: ¿qué podrías, en efecto, ver de más? Nada de nuevo: todo lo acostumbrado y de breve duración. Los ciclos del mundo son siempre los mismos, tanto arriba como abajo, de edad en e$\operatorname{dad}^{34, "}$.
Las dificultades invencibles que el pensamiento clásico encontró en el intento de fundar la libertad del hombre, nos son puestas muy en claro por Cicerón, en un paso del libro De Fato:

"A mi me parece que los filósofos antiguos siguieron dos doctrinas diversas; unos retenian que todo sucede por decreto del destino, de tal manera que este destino comunica a todo una fuerza necesaria. $A$ si pensaban Demócrito, Heráclito, Empédocles, Aristóteles. Otros juzgaban que existen movimientos voluntarios en el alma, independientes de todo destino. Crisipo, como árbitro honorario, ha querido escoger un camino intermedio: él se aproxima más bien a éstos que quieren que los movimientos del alma estén libres de la necesidad; pero, usando los términos que le son propios, se pierde en tales dificultades que llega a demostrar, aún contra su voluntad, la necesidad del destino,"35

Puede extrañar que entre los filósofos que someten todo al destino, Cicerón incluya también nada menos que a Aristóteles: pero si bien se considera que el primer motor inmóvil mueve todos los seres, se comprende fácilmente como también el hombre no pueda ser movido por el primer motor inmovible.

La afirmación de la libertad es más bien una exigencia práctica para el Estagirita, ( ¿De qué otro modo se podría hablar de responsabilidad y por tanto de sanción para el hombre?) que no mera consecuencia de las premisas y del desarrollo de su pensamiento. Recuérdense las primeras páginas de La Política aristotélica: Los hombres tienden al bien o mejor dicho, a lo que les parece a ellos ser el bien; pero para alcanzarlo deben unirse ya que el hombre y la mujer no pueden vivir separados: y así uniéndose el hombre con la mujer, se origina la familia. Para alcanzar un bien mayor, se unen entre ellos más familias en la $\kappa \cdot \dot{\omega} \mu \eta$, caserío; muchos caseríos dan origen a la $\pi \delta ́ \lambda \iota \varsigma$, la cual existe por naturaleza:

"Por esto es evidente - continúa Aristóteles- que la ciudad existe por naturaleza y 
que el hombre por naturaleza es un animal destinado a vivir en el Estado $\pi 0 \lambda \iota \tau \iota \kappa o ́ v \zeta \tilde{\omega} o \nu$ y que el hombre, que por naturaleza y no por suerte, no vive en

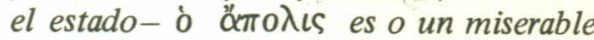
o un ser superior al hombre"36

He aquí, por qué la moral, según Aristóteles, establece normas en el actuar del hombre en cuanto éste vive en la sociedad (no tiene sentido hablar de moral individual): el fundamento de esta moral es la justicia. Y la aplicación de la justicia en concreto, es el orden de la comunidad de la vida dentro del Estado.

Por esto también Aristótelés se ve obligado a afirmar que el hombre es libre: si el estado es un hecho natural, un resultado de la naturaleza, el hombre debe ser libre. Y lo es efectivamente libre, cuando en sus acciones no experimenta violencia material o moral y cuando no ignora las circunstancias en las cuales debe actuar. La Acción es voluntaria cuando el individuo sabe perfectamente qué cosa hace, a quién lo hace, por qué lo hace. Entre las acciones voluntarias hay algunas que nosotros realizamos sin verificar una escogencia entre todas las posibilidades que se nos ofrecen: en tal caso se trata ahora de un deseo irracional y en tal caso es mejor hablar de espontaneidad, que no es todavía libertad. Cuando en cambio el bien está representado por la inteligencia, la acción que cumplimos depende de una escogencia ( $\pi \rho o \alpha i \rho \epsilon \sigma \iota \varsigma)$ la cual es precedida por una delibe-

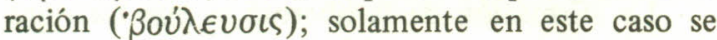
puede hablar de acción verdaderamente libre y por consiguiente, responsable; de hecho "parece que el hombre es principio de sus acciones"37.

Los estoicos fueron más coherentes que Aristóteles: en efecto no limitaron el determinismo al mundo físico, si bien lo extendieron a toda la realidad. Zenón, fundador de la escuela, admite la concatenación ininterrumpida de las causas: toda acción es efecto de 'una causa, que la ha precedido y a su vez es causa de un acontecimiento que le seguirá; esta cadena todo lo abarca; es la $\epsilon i \mu \alpha \rho \mu \epsilon^{\prime} \nu \eta$, "la potencia que mueve la materia; él la llamó también providencia o naturaleza"38

A este ligamen, observa Crisipo, segundo fundador de la escuela, nada se sustrae; aún aquellos eventos, que parecen contradecir a las leyes inmu- tables, están ya previstos y queridos por la $\epsilon i \mu \alpha \rho \mu \epsilon ́ \nu \eta$. Ella es la divinidad suprema, a la cual todo está sometido, también los dioses y con mucha mayor razón los hombres. Nosotros, mortales, no podemos menos de seguirla. Zenón y Crisipo comparaban al hombre con un perro encadenado a un carro en movimiento; quiera o no quiera, el perro debe seguir el carro, el hombre debe seguir la $\epsilon i \mu \alpha \rho \mu \epsilon ́ \nu \eta$.

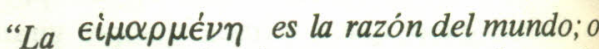
bien la razón de esto que en el mundo está gobernado por la providencia; o bien la razón según la cual lo que ha sucedido sucedió, lo que sucede, se realiza, lo que sucederá, se verificará" 39

Ella es llamada también verdad, causa, naturaleza, necesidad y de otras maneras más.

\begin{abstract}
Para ella todo está ya establecido: "También las leyes y las exhortaciones $y$ las sanciones y las disciplinas y toda otra cosa del género, todo depende de condiciones fatales ... Semejante criterio es válido para las alabanzas, vituperios, castigos, premios. "40
\end{abstract}

El principio de toda la realidad es uno solo: Dios y el mundo, materia y espíritu son una sola cosa e idénticos; nada puede estar fuera de la serie de causa y efecto. E1 destino no existe. La armonía del todo excluye la posibilidad que cualquier cosa se realice fuera del nexo causal.

Ahora podremos darnos mejor cuenta de la eterna cíclica realización de todas las cosas, la cual referiremos con las palabras de Nemesio:

\footnotetext{
"Dicen los Estoicos que los astros errantes cuando retornan al mismo signo y según la longitud y latitud, donde cada uno de ellos estaba desde cuando el mundo desde un principio se constituyó, en los ciclos prefijados de los tiempos, producen conflagración y destrucción de todo lo que existe; y que de nuevo el cosmo tien-
} 
de a ser como era en un principio. $Y$ dado que los astros de nuevo se mueven del mismo modo, cualquier acontecimiento que hubiera ya sucedido en el ciclo precedente, tienden a cumplirse sin ninguna variación. En efecto existirá de nuevo Sócrates y Platón y cualquiera de los hombres con los mismos amigos y con los mismos conciudadanos y a cada uno le sucederán las mismas cosas y encontrará a las mismas personas y hablarán de los mismos argumentos; $y$ toda ciudad, villa $y$ campiña retornará en la misma forma. $Y$ este universal retorno al prístino estado acontece no una sola vez, mas repetidas veces, al infinito y sin fin las mismas cosas retornan... nada de extraño habrá excepto lo que ha acontecido antes, pero todo en el mismo modo e inmutablemente, hasta las minimas cosas. "4 1

\section{Y, ¿la libertad?}

Ciertamente para los estoicos no puede existir libertad, entendida como acción independiente de causas que necesariamente la determinen; el hombre, como todo otro ser, está rigurosamente determinado y no puede no ser aquello que es y no puede no hacer esto que hace.

Y con todo, el hombre cuando busca qué debe deliberar, delibera si debe hacer una cosa o bien el contrario; y así se comporta también quien está convencido que todo sucede de acuerdo con el destino:

\footnotetext{
“la verdad, que existe en los hechos, confuta las opiniones equivocadas relativas a los hechos mismos." 42
}

observa Alejandro de Afrodisia, comentador de Aristóteles, en el tratado $\pi \epsilon \rho i \in i \mu \alpha \rho \mu \epsilon ́ \nu \eta \varsigma$. Tampoco los estoicos pueden negar que la libertad es un hecho de conciencia. Crisipo se devana los sesos por salvar de cualquier modo la libertad; pero su doctrina no le consiente más que admitir la espontaneidad de ciertos actos humanos; pero espontaneidad no es libertad. La acción del hombre es libre si depende sólo de causas internas; no es libre si está determinada por causas externas. De acuerdo con esto Crisipo distingue causas perfectas y principales o causas auxiliares y próximas.

"Si todo acontece fatalmente observa el mencionado filósofo- se sigue que todo acontece por fausas precedentes; que no son, sin embargo, causas principales y perfectas, sino auxiliadoras y próximas. Ahora si éstas no están en nuestro poder, no se sigue que tampoco la tendencia no esté en nuestro poder." 43

Esta distinción salva, según decir de Crisipo y de los estoicos, la responsabilidad del hombre; en realidad no salva sino la espontaneidad psicológica. Pero también esta espontaneidad es elemento necesario del universo y por esto reingresa en el proyec-

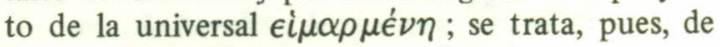
una espontaneidad puramente ilusoria.

Así con los estoicos el pensamiento antiguo ha alcanzado un punto más allá del cual no avanzará. El estoicismo predica la resignación al destino, la aceptación de la propia condición; el hombre se repliega sobre sí mismo, para vencer dentro de sí mismó la batalla, para seguir de buen grado el destino, como el perro, que corre detrás del carro en movimiento, al cual está amarrado y así evita ser arrastrado. Ideal de vida para un mundo fatigado y desilusionado; para un múndo que no concibe más grandes esperanzas: es el mundo griego que ha perdido la libertad política y, juntamente a ella, todo papel de importancia real en las vicisitudes de la historia.

Nada de extrañarse si estas doctrinas serán acogidas con favor y defendidas también por la sociedad culta de Roma en tiempos del imperio, cuando entonces la libertad republicana estaba viva en el recuerdo y aparecía como un bien perdido para siempre.

Séneca proclama:

"No experimento constricción, no sufro nada contra mi voluntad: no soy ésclavo de Dios, si bien doy mi consentimiento a su voluntad, tanto más porque sé que todo pasa según una ley fija y establecida por la eternidad. El destino nos guia y el peligro del tiempo, que a cada uno afecta, está establecido desde la primera hora de 
existencia. De una causa viene la causa; una larga serie lleva consigo misma los acontecimientos privados y públicos. Por esto es necesario soportar todo con fortaleza, ya que nada acontece por casualidad, no obstante que todo llega a nosotros",44

Vuélvese norma de vida para ocasiones tristes o grises, el siguiente pensamiento:

“'Por qué, pues, desdeñarse? ¿Por qué. lamentarse? Por esto hemos sido engendrados ... ¿Cómo se comporta el bueno? Se rinde al destino. Gran consuelo es el ser llevado lejos junto con todo el universo." 45

Esta voluntad firme de aceptar el propio destino se resuelve en amarga resignación en las palabras del emperador filósofo:

"Cualquier cosa que te acaezca, estaba destinado para ti desde la eternidad: y la concatenación de las causas habia ya desde la eternidad entretejido aquel evento con tu existencia" 46

A esta doctrina, que se resuelve en la negación de toda efectiva responsabilidad de la acción humana, se contrapone la fe epicúrea en la libertad entendida como elegida no determinada por alguna causa, entre un sin número de posîbilidades que todas se ofrecen al hombre. Que precisamente el sistema de Epicuro, el cual cámbia la física de Demócrito, tenazmente propugne la libertad, es algo inexplicable. En efecto, ¿qué sentido tendría el pensamiento de Epicuro, si fuera y encima del hombre existiese una providencia o un hado?

El alma nóo se podría sustraer a la ley de la necesidad mecánica, reguladora de los átomos, ya que el alma misma es un agregado de átomos; de aquí la necesidad de introducir un principio de indeterminación, para Epicuro, el clinamen, gracias al cual la casualidad y la libertad no pueden distinguirse el uno del otro. Y entonces aparece LUCRECIO explicándonos que para salvar la libertad del hombre, no quedaba otro remedio más que "romper las leyes del destino"47 Pero la doctrina de la declinación de los átomos suscitó fáciles críticas y Cicerón llegó a afirmar que si, de verdad no existiese otro medio, para salvar la libertad, de estas argumentaciones epicúreas quedaría demostrado no solamente el destino sino también la necesidad"48

También Carnéades se refirió contra el hado estoico, preguntando cómo es que si todo obedece a una ley racional, en el mundo existe la imperfec. ción y el mal, en una palabra lo irracional y lo que está privado de la razón. Para él la libertad es un fundamento en la vida de los hombres que es necesario admitir, a fin de salvar, aún una vez más, la moralidad, es decir la responsabilidad. Admitido el fatalismo, no tiene sentido la alabanza y el reproche, la ley penal y la justicia, la plegaria a los dio'ses y la religión, no existen más la virtud y el vicio. Con esta práctica demostración de las gravísimas consecuencias a las cuales conduce la negación de la libertad, Carnéades cree conseguir postular la libertad del hombre.

Como se ve, puntos de llegada de la reflexión filosófica con respecto al problema de la libertad son ẹn el mundo clásico, o la negación sustancial de la libertad o bien la fe en ella como fundamento no eliminable de la sociedad humana.

Pero esta desconcertante parábola de la reflexión filosófica sustancialmente coincide con la curva que la libertad política describió en la historia de Grecia y Roma.

Grecia tiende en su desarrollo histórico a afirmar y a realizar formas de libertad siempre más altas. Los griegos de Pericles son conscientes de que su propio destino tiene el nombre de libertad ("Este es el nombre más bello: ioovouín proclama Heródoto, el historiador de la victoriosa resistencia al bárbaro invasor y que los otros pueblos, los bárbaros, están por naturaleza destinados a la esclavitud.

Eurípides canta:

"Es natural que los Helenos manden a los bárbaros, pero nunca que los bárbaros manden a los Helenos; los bárbaros son raza de esclavos, los Griegos raza de hom. bres libres." 49 


\section{Y Aristóteles confirma:}

"Causa de todo esto es el hecho de que los bárbaros por naturaleza no están desti-

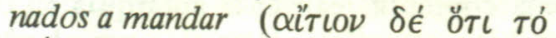

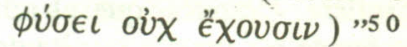

Heródoto suministra la prueba de que los.bárbaros han nacido para ser esclavos, cuando refiere la supuesta deliberación en torno a los tres regímenes (democrático, iligárquico, monárquico), sostenida por los conjurados persas que habían eliminado al falso Esmerdo; no obstante el elogio de la democracia, valga decir de la libertad, hecha por Otane, uno de los conjurados, los restantes de la conjuración escogen sin mayor discusión el régimen monárquico.

Los griegos, por su parte, están hechos para la libertad y deben por esto, tender a realizar aquella constitución que conceda a los individuos, en la mayor manera posible, la libertad. Esto se obtiene con la democracia, porque afirma Aristóteles:

\section{"Fundamento de la democracia es la li- bertad: esto en efecto se suele decir como si sólo en esta forma de gobierno los hom- bres tienen parte de la libertad; dicen, en verdad que a este fin tiende toda demo- cracia" 1}

Democracia significa igualdad fundada no sobre el mérito, sino sobre el número; en ella la soberanía reside en el pueblo en su totalidad; el querer de la mayoría tiene fuerza de ley, porque todos los ciudadanos son iguales.

La organización del estado democrático exige:

1) que los magistrados sean elegidos mediante sufragio universal.

2) que todos los ciudadanos puedan ser llamados a ejercer la magistratura.

3) que los cargos (todos o al menos aquellos que no requieran experiencia o capacidad técnica) sean conferidos por suerte.

4) que como norma nadie ejerza dos veces el mismo cargo.
5) que todos los ciudadanos entren a formar parte de los tribunales.

6) que la asamblea de todos los ciudadanos sea soberana.

Estas son más o menos, según Aristóteles, las características de la democracia; en el mismo modo ' ya la había exaltado el mismo Heródoto por boca de Otane. ${ }^{52}$

También Eurípides escogió un himno a la democracia ateniense, en Las Suplicantes, cuando por boca de Teseo habla al heraldo tebano:

“Tú, oh extranjero, has comenzado tu discurso equivocándote, ya que aqui buscas un tirano: 'aqui no manda un solo hombre: la ciudad es libre! El pueblo es soberano; todos los ciudadanos por duración de un año tiene el gobierno; ninguna ventaja se da al dinero; pues el pobre y el rico gozan de los mismos derechos." 53

$\mathrm{Y}$ en el contraste con el heraldo, que sostiene la superioridad de la forma monárquica, Teseo defiende apasionadamente la democracia, proclamando que la libertad consiste sobre todo en la posibilidad concedida a todos los ciudadanos de exponer libremente el propio pensamiento.

El pintor Eufranor, interpretando también él el común sentimiento de los atenienses, representó en el Pórtico de la Libertad, que surgía en la ciudad de Atenas, a Teseo llevando la Democracia como esposa al pueblo de Atenas.

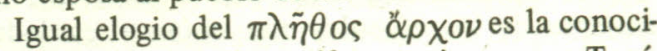
dísima oración por los caídos atenienses que Tucídides hace pronunciar a Pericles:

\footnotetext{
"Su nombre es demócracia. Por ley todos los ciudadanos participan de los mismos

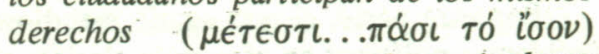
en cuanto a las controversias privadas; $y$ en cuanto a la vida del Estado, cada uno, según la estimación de que goce, es honrado más por su virtud que no por la clase social a quel pertenece" 54
} 
Pero esta libertad a la cual esencialmente mira la constitución democrática, no era realmente entendida como un valor absoluto; no se identificaba con la felicidad, es decir con el bien, que es el verdadero fin del hombre. De esto parece darse cuenta Aristóteles, cuando observa que el vivir como cada uno quiere es considerado uno de los caracteres de la democracia ${ }^{55}$ de esto se origina la consecuencia que no existe sumisión; en el caso más favorable nadie se somete a ninguno; si esto no acaeciera, la sumisión solamente existe en parte. Otán, cuando su propuesta de instaurar la democracia en el imperio persa no es"acogida, declara a los otros: "Yo no quiero ni mandar ni ser mandado; con esta condición me retiro del mando; que, ni yo ni mis descendientes tengamos que estar sometidos a alguno de vosotros". Y comenta Heródoto:

\footnotetext{
"también en nuestros tiempos aquel linaje, entre los persas, continúa siendo libre $y$ obedece solo en la medida que quiere, sin transgredir, sin embargo, las leyes persas. ${ }^{56} 6$
}

He aquí por qué la democracia ateniense no contenía en sí gérmenes verdaderamente fecundos y capaces de desarrollo: con el curso de los decenios la misma se reveló como un programa egoísta tendiente a exaltar al individuo y a favorecerlo en frente de la sociedad; no significó apertura hacia los otros; antes bien la democracia griega insensiblemente cayó en el peligroso error que tanto más segura sería la libertad en cuanto menor fuese la sujeción del ciudadano al estado: e hizo coincidir sustancialmente el desarrollo y el perfeccionamiento de la constitución política con el progresivo aflojamiento de los vínculos que unían el ciudadano con el estado. Así se explica por qué Grecia no resistió el choque con la potencia macedónica y por qué los griegos de la $\pi \delta ́ \lambda \epsilon \iota \varsigma$ en el siglo IV estaban listos para abrazar los ideales de vida intelectual de las nuevas escuelas filosóficas, valga decir, la estoica y la epicúrea.

Por otra parte, el más agudo estudioso de los problemas políticos en el mundo clásico, el Estagirita, reconoció al Estado una tarea que es aquella de vivir bien, para realizar una vida perfecta y autosuficiente ${ }^{57}$; pero consideró como medio idóneo y perfecto, en miras a tal fin, la $\pi \delta^{\lambda} \iota \varsigma$, cuya población no debe ser muy numerosa, pues cuando es así, difícilmente su gobierno puede ser bueno. Y la ciudad, cuyo gobierno es bueno, se preocupa del excesivo aumento del número de ciudadanos. En suma, la población debe ser tan numerosa que pueda consentir realizar la autarquía en cuanto al vivir bien se refiere. Después, que el número de ciudadanos no pueda ser grande resulta de la recomendación que Aristóteles dirige a los ciudada. nos: que se conozcan íntimamente el uno al otro, como es necesario que suceda teniendo en cuenta los juicios que han de ser pronunciados en los tribunales y de las magistraturas que deben atribuirse de acuerdo con los méritos. ${ }^{58}$

Así Aristóteles ve el paso de la familia al caserío y de éste a la ciudad; pero en ésta puso la perfección. Porque si es verdad que todas las asociaciones tienden a algún bien, aquella asociación que es de todas señora y a todas las otras abarca, deben tender el Bien que es el soberano de todos los bienes; y esta asociación es aquella que se llama $\pi \lambda_{\imath \iota \varsigma}$ y sociedad política ${ }^{59}$

En el desarrollo de las formas de vida asocia. da, no se puede ir más allá de la $\pi$ ó $\iota \varsigma$; también por esta vía el mundo griego se encontró desarma. do de frente a los grandes organismos estatales, como fue primero Macedonia y después Roma.

En suma, en el mundo griego a la imposibili. dad de demostrar convincentemente la libertad, en la cual no obstante se creía, corresponde la incapacidad de realizarse históricamente.

\section{$* * *$}

Si ahora pasamos a considerar la libertad en Roma, no se nos hace difícil constatar cómo la reflexión filosófica en torno al significado de la libertad no haya mínimamente progresado respec. to a los resultados obtenidos por el pensamiento griego.

Esto bien se explica si se considera que para los romanos la libertad venía identificada con el disfrute de los derechos civiles. Pero ya que bajo el dominio de uno solo los derechos civiles no son garantizados, esta libertad excluye el régimen monárquico. Los embajadores romanos declaran a Porsenna: 


\section{"non in regno populum Romanum sed in libertate esse" 60}

El deseo de los romanos es éste: que la libertad se extienda hasta donde se extiende la Urbe; porque ésta sólo en la libertad puede ser salvada. El régimen republicano, instaurado después de la expulsión de los reyes, tendió ante todo -al menos en la interpretación de los historiadores y políticos de roma que reflexionaron sobre aquellos acontecimientos- a permitir a todos los ciudadanos la fruición de los derechos civiles. De esta coincidencia nació en la conciencia de los romanos la convicción de que el régimen republicano y la libertad se identificaban.

Por este camino se procedía a dar un ulterior ahonde en la idea de la libertad; ésta venía ahora a revelarse como derecho y deber al mismo tiempo. En efecto ésta tenía su término de referimiento,no simplemente en el arbitrio del individuo, sino en la ley, en cuanto los derechos del ciudadano estaban fijados por la ley. Ser libre quería decir, ante todo, obedecer a las leyes. Los romanos eran conscientes que bajo este aspecto ellos habían progresado respecto a los griegos y Cicerón observaba precisamente que la antigua Grecia, después de haber brillado por sus riquezas, imperio, gloria, decayó por un único mal, por la inmoderada libertad y por la licencia en los discursos ${ }^{61}$. Es necesario que la libertad sea templada: sólo así ésta es saludable, benéfica a los individuos y a los estados ${ }^{62}$.

Libertad templada: ¿pero por parte de quién? ¿Y de qué cosa? ¿Con quién y con qué cosa se conmensurará la libertad?

Responde Cicerón:

\section{"lagun idcirco omnes servi sumus ut liberi esse possimus" 63}

Por esto el romano se siente sujeto a la ley; pero las leyes son hechas por los hombres. Es decir, el límite a la libertad del ciudadano está puesto, mediante la ley, por el ciudadano mismo.

$\mathrm{Y}$ así la libertad se mantiene hasta que, en el equilibrio de poderes, cada ciudadano goza sustancialmente de los derechos inherentes a su calidad de ciudadano; pero cuando este equilibrio se rompe, la libertad está destinada a abismarse y a desaparecer.
Polibio declara que la constitución Romana es la más perfecta casualmente porque es mixta, es decir compuesta de la monarquía, aristocracia, democracia; con el sistema de los controles y contrapesos los poderes (legislativo, ejecutivo, judicial) se equilibran. He aquí porqué en Roma, aquellos que por méritos reales o por avidez de poder parecen poner en peligro o realmente ponen en peligro tal equilibrio (como por ejemplo el caso de Tiberic Graco y Saturnino), pronto son acusados de aspirar al regnum (es decir de querer terminar con la libertad) y tiranías fueron juzgados los gobiernos de Cinna y Sila.

Pero cuando, con el crecer siempre más y más la mole del estado, fue transformándose lentamente el régimen republicano en una república aristocrática, el equilibrio fue poco a poco desapareciendo, se habían puesto ya las premisas para el fin de la libertad.

Con todo, si la libertad es el disfrute de los derechos del ciudadano, ésta no es un valor absoluto, al cual el hombre no pueda renunciar. Perdidos aquellos derechos, el ciudadano no será más ciudadano, pero permanecerá siempre hombre, como era también antes.

Por esto se combatió tan ásperamente, para defender lo que quedaba del antiguo régimen, contra César y contra los Triunviros; pero al fin el dominio de uno solo se instauró y pudo, éste único, OCTAVIANO AUGUSTO, declarar con toda tranquilidad ser el vengador de la libertad, haber restaurado la libertad, haber conferido a los ciudadanos sus derechos; pero estos derechos no eran más, en sustancia, aquellos de un tiempo, aunque muy semejantes o idénticos en la forma. Libertad bajo tutela no es libertad. Libertad que depende del arbitrio de uno solo (el príncipe) no puede ser llamada, si no es por burla, libertad. La concepción jurídica de la libertad no bastó más a los romanos, cuando el régimen político, del cual aquella era expresión y casi símbolo, cayó. Para no admitirlo, sería necesario creer de verás que los romanos, a partir de la época de Augusto, no se hubieran dado cuenta de que vivían entonces bajo otro régimen y que, para salvar el concepto de libertad, era necesario dar a ésta un nuevo fundamento y sobre todo un nuevo contenido. Ha de creerse que así haya sucedido, tanto más que no son pocos ni tampoco despreciables las señales de la influencia del pensa- 
miento filosófico en particular estoico, por aquella época.

Para el estoicismo los hombres son todos iguales, no existen esclavos por naturaleza, no existen diferencias de Estados homo sacra res homini, como proclama Séneca ${ }^{64} ; y$ el rey, galanteado por los estoicos, declara:

"Todos los hombres, desde el primero hasta el último, aunque falten de todo, por el solo nombre de hombre, gozan de mi favor". ${ }^{65}$

Pero el dominio de uno solo viene a negar tal derecho natural.Entonces-la oposición bajo el principado sustituye el concepto jurídico de libertad, válido en la edad republicana, el mito de la libertad natural conculcada por el dominio de una sola persona. A esta fe revolucionaria la propaganda imperial buscaba contraponer el patriótico mito de la pax perpetua fundado sobre la fe en la eternidad de Roma.

El conflicto se resolvió, como se sabe, a favor de los príncipes. Los hombres se resignaron a cambiar la libertad por la paz: después de la batalla de Accio, nos dice Tácito:

"Fue útil a la paz que todo poder estuviese confiado a uno solo" 66

\section{Así que César Augusto}

"Dio leyes para que tuviéramos la paz y un principe" 67

Plinio, en el Panegírico a Trajano, se obstina en proclamar que los romanos son libres. El dice:

"Es verdadero que estemos gobernados por ti (es decir por el Príncipe) y que seamos todos tus súbditos, pero nosotros te estamos sujetos como a las leyes. "68

Y todavía, siempre dirigiéndose al príncipe:
"Tú nos mandas ser libres y nosotros lo seremos; tú nos ordenas manifestar abier. tamente nuestro pensamiento y nosotros lo manifestaremos."

¡Este es el fin más triste de la libertad!

La ciudad estoica del mundo permaneció siempre como mera abstracción y fue solamente un refugio ideal para el sabio más que todo para favorecer y justificar el aislamiento de los otros hombres, que no por constituir la base sobre la cual fundar una nueva humanidad. Fue elemento de disgregación y no de cohesión. El mundo antiguo estaba ya encaminado hacia su inevitable fin.

Entre tanto ya se había difundido entre los hombres, que siempre más numerosos la seguían, una nueva doctrina por la cual "con la ayuda de Dios Señor nuestro, nuestra razón manifiestamente despedaza aquellos volubles ciclos del tiempo que la opinión imagina", como dice San Agustín ${ }^{69}$. El cristianismo se representa el tiempo como una línea recta, un rectum iter, en donde todo aconte. cimiento sucede una vez y una sola vez y por esto es irrepetible:

"Christus semel pro peccatis nostris mortuus est"70

La suerte de cada hombre se decide una vez y de una vez para siempre, en el tiempo: la historia tórnase antropocéntrica y teleológica; el mundo es para èl hombre y cada hombre es una persona, cuyo valor es infinito. El mundo ha sido creado por Dios en el tiempo y por un acto libre de su voluntad movida por el amor. Es inútil proponerse la explicación de por qué es así como es. El hombre es creado libre por Dios, todos los hombres son hijos de Dios y, por esto, somos los hombres hermanos. Sin embargo con el pecado original el hom. bre permanece esclavizado al pecado: 
"pero cuando -dice el apóstol Pablo-llegó la plenitud de los tiempos, Dios envió su Hijo nacido de mujer, nacido bajo la ley, a fin de que rescatase a aquellos que estaban bajo la ley y para que fuésemos adoptados como hijos. Y ya que sois hijos, Dios mandó a nuestros corazones el Espíritu de su Hijo... De tal manera no sois más siervos, sino hijos: y si sois hijos también herederos de Dios ${ }^{71}$ ",

Esta es la promesa de Cristo:" ì $\alpha \lambda \dot{\eta} \theta \epsilon \iota \alpha$ $\dot{\epsilon} \lambda \epsilon v \theta \epsilon \rho \omega \tilde{\omega} \sigma \epsilon \iota \dot{v} \tilde{\alpha}{ }^{72}$

E1 ha traído la verdad para que el hombre sea libre; porque "El Señor es Espiritu: donde está el Espiritu ahi está la libertad"73

El cristianismo reconoce como una verdad axiomática que la voluntad del hombre es libre y gracias a la inmolación del Hijo de Dios sobre el patíbulo de la cruz.
"La criatura misma será libertada -dice San Pablo en la carta a los Romanos - de la esclavitud de la corrupción por la libertad de la gloria de los hijos: de Dios"74

Escribió Lord Acton en su Historia de la Libertad. ${ }^{75}$ que "la nueva ley, el nuevo espiritu, la nueva autoridad, daba a la libertad un significado y un valor, que ésta no poseia en la filosofía o en la, constitución de Grecia o de Roma antes que se conociese la verdad que nos hace libres".

Y así el mundo antiguo lentamente se extinguía y moría en las conciencias de los hombres, pero a su vez un nuevo mundo de hombres nuevos lenta y fatigosamente nacía y crecía a la sombra de la Cruz.

\section{NOTAS BIBLIUGRAFICAS}

1) Germ., 46.

2) Agr., 3

3) 44,35

4) Agr., 42.

5) Ibid.

6) Ann., 14-12

7) Ann., 16,35

8) Agr., 3.

9) De-benef., 7,82

10) Ann., 15,65.

11) 8. 211-2

12) Resp. 473 d.

13) Lucian., 25,3

14) Crat. apud Clement. Strom. 2,20, 121, 1 St.

15) Lucian., 'Cyn. 12.;

16) Diog. L., 6, 11.

17) Diog. L., 6, 72.

18) Diog. L., 6,63.

19) Ann. 6,22.

20) De Ira, 3,15 ; cfr. de prov., 5,8 .

21) De const. sap., 19,3.

22) Epict., Man. 53.

23) Epist., 107,11.

24) Problem., 17,3.
25) Phys., 8, 13,265.

26) Vv. 34-6.

27) Ibd., 5-6.

28) $6,713-4$.

29) D.K., 14,8 a.

30) Orig. II, 3,4 .

31) D.K., 24 B 2.

32) De consul. Stilich., II, 430

33) Manil., Astron. I.521

34) VII, $19,49,1$

35) 17,39 .

36) $1,1,9$.

37) Eth. Nic., 5, 1112 b 31.

38) S.V. F., 1, 176

39) S.V.F. II, 913

40) S.V.F., II,943

41) De nat. hom., 38.

42) 12,40

43) S.V.F., II, 974 (Cic., De fato, 18-41)

44) De prov., $5,7$.

45) Ibid., 8.

46) 10,5 .

47) II, 254.

48) 3,81 . 
49) Iphig Aul., 1400-1.

50) Polit., $1,1,5$.

51) $3,80-3$.

52) Polit. 6,2,6,

53) 3,80 .

54) $403-408$.

55) 2, 37.

56) Polit., 6, 2, 7

57) Polit. 3,5,13.

58) Polit. 7, 4,7

59) Id., $1,1,1$

60) Liv., 11,15.

61) Cic., Pro Flaccor 7,16

62) Liv., 34, 49,8 .
63) Pro Cluent., 146.

64) Epist., 95,33.

65) Senec., De clem., 1,1,3.

66) Hist., 1,1,1.

67) Ann., 3,28,3.

68) 24,4 .

69) De civ. Dei 12,18

70) 1 Petr., 3,18; cfr. Ad Hebr., 9, 12, 28.

71) Ad Gal., 4,4-7.

72) Ioann., 8,32.

73) Ad. Corm, II.3,17

74) 8,21 .

75) Pág. 29. 